\title{
Erratum to: The outcome of primary brachial plexus reconstruction in extended Erb's obstetric palsy when two roots are available for intraplexus neurotization
}

\author{
Mohammad M. Al-Qattan ${ }^{1}$ - Amel A. F El-Sayed ${ }^{2}$
}

Published online: 26 May 2017

(C) Springer-Verlag Berlin Heidelberg 2017

Erratum to: European Journal of Plastic Surgery

DOI 10.1007/s00238-016-1267-6

The article The outcome of primary brachial plexus reconstruction in extended Erb's obstetric palsy when two roots are available for intraplexus neurotization, written by Mohammad M. Al-Qattan \& Amel A.F El-Sayed, was originally published electronically on the publisher's internet portal (currently SpringerLink) on 06 January 2017 without open access.

With the author(s)' decision to opt for Open Choice the copyright of the article changed on 25 May 2017 to $\odot$ The Author(s) 2017 and the article is forthwith distributed under the terms of the Creative Commons Attribution 4.0 International License (http:// creativecommons.org/licenses/by/4.0/), which permits use, duplication, adaptation, distribution and reproduction in any medium or format, as long as you give appropriate credit to the original author(s) and the source, provide a link to the Creative Commons license and indicate if changes were made.

The original article was corrected.

The online version of the original article can be found at http://dx.doi.org/ 10.1007/s00238-016-1267-6

Mohammad M. Al-Qattan

moqattan@hotmail.com

Department of Surgery, King Saud University, Riyadh, Saudi Arabia

2 Department of Obstetrics and Gynecology, King Saud University, Riyadh, Saudi Arabia 